\title{
A NOD/SCID Model of Primary Human Breast Cancer
}

\author{
Vivienne M. Peut ${ }^{1}$ and Alison M. Rice ${ }^{2,3, *}$ \\ ${ }^{I}$ Department of Microbiology and Immunology, University of Melbourne, Australia; ${ }^{2}$ Mater Medical Research Institute, \\ (MMRI) Brisbane, Australia and ${ }^{3}$ Faculty of Health Sciences, University of Queensland, Australia
}

\begin{abstract}
Background: Breast cancer kills about 400000 people annually worldwide. Whilst the conventional therapy of surgery, radiation, chemotherapy and hormone therapy has increased survival rates dramatically, the relapse rate is intolerably high. New therapies, particularly immunotherapies, required to combat this residual disease would ideally be tested on an animal model. Current animal models of human breast cancer available for testing new therapies are unreliable. We therefore sought to develop a protocol that will enable the reliable and reproducible production of a xenograft murine model of human breast cancer.

Methods: Female NOD/SCID mice, under specific pathogen-free conditions, were inoculated subcutaneously in the inguinal mammary fat pad area with either dissociated primary breast tumours or the breast cancer cell line MCF7. Variables tested included irradiation of mice prior to inoculation, differing tumour cell numbers and the use of the commercial basement membrane Matrigel.

Results: $100 \%$ engraftment and growth of both MCF7 cells and dissociated primary breast tumour cells, coinoculated with Matrigel, was achieved regardless of whether the mouse was irradiated or not, however larger tumour volume was achieved in the non-irradiated mice. The largest inoculum, $5 \times 10^{6}$ cells of MCF7 cells, gave the largest tumours after 3 months in situ ( $\mathrm{p}=0.006)$. The number of cells injected from primary tumours did not correlate with final tumour size. Both MCF7 and primary human breast tumours exhibited the layered nature of breast tumours, with living cells on the periphery and necrotic cells in the interior. MCF7 cells that engrafted maintained their ER+, CD24+, CD44+ BC2+ (MUC1+) status after in vivo growth. All tumours became vascularised but no metastasis was evident.

Conclusions: This is a simple and reliable protocol that ensures human breast tumour growth in the NOD/SCID mouse. This model is valid, in that the tumours are orthotopic, they have the layered nature of human breast tumours, become vascularised and maintained the surface and nuclear marker status tested for. It has potential as a valid human breast cancer test bed for preclinical testing of immunotherapies and anti-angiogenesis agents.
\end{abstract}

\section{INTRODUCTION}

The pursuit of a valid murine model of human breast cancer has occupied researchers for decades. Nude mice were the mainstay of xenotransplant modelling until 1993 [15]. A major step forward in the development of a more immunodeficient mouse strain was the identification of the Severe Combined Immunodeficicent (SCID) mouse [6]. Kubota and co-workers were among the first to demonstrate that the SCID mouse was as good as, if not better, than the Nude mouse for xenotransplant experiments with $60 \%$ breast cancer growth in Nude mice and $65 \%$ for SCID mice [7]. Using this model, Visonneau and colleagues achieved $100 \%$ engraftment rate for human breast tumours samples [8]. Of note is that one year later this same group could only achieve $50 \%$ tumour growth with the same protocol, mouse strain and implants [9], highlighting the unreliability of the SCID model of human breast cancer.

The functional innate immune system of the SCID mouse was under suspicion as the source of inconsistency of breast tumour uptake rates. The NOD mouse, which has mutations at multiple loci, is deficient in NK cells, complement and

*Address correspondence to this author at the Mater Medical Research Institute, Level 3, Aubigny Place, Raymond Terrace, South Brisbane, 4101, Queensland, Australia; E-mail: arice@mmri.mater.org.au have dysfunctional antigen presenting cells [10]. Development of the NOD/SCID mouse which has combined defects in the innate and adaptive immune systems led to their use in preference to the SCID mouse for xenotransplantation of human breast carcinomas [11]. Beckhove, Bai, Feuerer and colleagues have had considerable success with the NOD/ SCID mouse strain, recording $90-93 \%$ engraftment of human breast tumours [11] and achieving tumour regression in vivo $[12,13]$.

Irradiation destroys the haematopoietic tissue and suppresses the immune system. Beckhove and colleagues conducted a well designed experiment in which direct comparisons were done between the engraftment rates of human breast tumour and MCF7 in irradiated (3.75Gy) and non irradiated NOD/SCID mice [11]. The 93\% uptake for irradiated mice was largely negated by the high, early mortality rate. Non-irradiated animals registered $90 \%$ tumour growth, however engraftment rates were still inconsistent. Compounds that promote primary human breast cancer growth in vivo are clearly required if this model is going to be of use as a preclinical platform to test new breast cancer therapies.

The basal lamina, sheets of extracellular matrix, influence cell metabolism, proliferation, survival, differentiation, organisation and migration [14]. An artificial basal lamina 
such as Matrigel, when administered with the foreign tissue, enhances engraftment by facilitating the processes of cell adhesion, migration and proliferation. A study comparing subcutaneous (SC) uptake rates of xenografts in nude mice showed significant improvement if Matrigel was added to the cell suspension [15]. This strategy was subsequently used by numerous groups [11-13, 16]. Two of these groups, Beckhove and Al-Hajj, reported between 90 and $100 \%$ engraftment rates in NOD/SCID mice [16, 17]. Beckhove and coworkers have extended this, showing tumour engraftment and growth after surgical implantation, without coinoculation with Matrigel, in the NOD/SCID model after 16 days post tumour implantation [17].

We were interested in developing novel immunotherapeutic strategies as adjunct therapy for breast cancer. The inconsistency and unreliable nature of the current murine models of primary human breast cancer is a significant rate limiting step. A protocol was required to simply and reliably grow human breast cancer cells in mice as a test bed for new therapies. Such a method is reported here.

\section{METHODS}

\section{Mice}

4 week old female NOD/SCID mice were sourced from the Walter and Eliza Hill Institute, Victoria. All animal work was approved by the University of Queensland Animal Ethics Committee. Mice were allowed to acclimatise for 7 days prior to any procedures. Mice were housed in microisolator cages and provided with autoclaved food and water. In some experiments mice received total body irradiation (TBI) of 250cGy in a Gammacell 40 Exactor (MDS Nordion) 24 hours prior to tumour cell inoculation.

\section{Primary Tumours}

Tumours were obtained from women with newly diagnosed breast cancer. All experimental work was approved by the Mater Health Services Human Research Ethics Committee. Patient age and tumour grade were not restricted, however tumour diameter had to exceed $2 \mathrm{~cm}$ diameter. Six primary tumours were suitable for inclusion in this study, as listed below in Table $\mathbf{1}$.

\section{Tumour Dissociation}

Tumour samples were collected and processed immediately. Each tumour was washed in Hanks Balanced Salt Solution / Glutamine / Penicillin / Streptomycin (HBSS / GPS) (Sigma), solution to remove pathology ink, blood and fat. The cleaned specimen was then transferred to a $9 \mathrm{~cm}$ petri dish and $5 \mathrm{mLs}$ of $0.1 \%$ collagenase I solution (Powdered Collagenase I (Sigma) dissolved in HBSS to produce a $1 \%$ dissociation solution) was added. The tumour was then minced using scalpel blades and the resulting mixture transferred to a sterile $50 \mathrm{~mL}$ Schott bottle with magnetic stirring rod. After addition of another $30 \mathrm{~mL}$ collagenase solution, the mixture was stirred at room temperature for between 2 and 18 hours to produce a solution free of visible fibrous matter. The single cell suspension of breast cancer cells was washed with HBSS/GPS and centrifuged at $2000 \mathrm{rpm}$ for 10 minutes. The pellet was resuspended in $50 \mu \mathrm{L}$ PBS for the SC inoculation.
Table 1. Primary Tumour Pathology and Histology

\begin{tabular}{|c|c|c|c|}
\hline $\begin{array}{c}\text { Primary } \\
\text { Tumour ID }\end{array}$ & $\begin{array}{c}\text { Tumour } \\
\text { Histology }\end{array}$ & $\begin{array}{c}\text { Primary } \\
\text { Tumour ID }\end{array}$ & $\begin{array}{c}\text { Tumour } \\
\text { Histology }\end{array}$ \\
\hline MOPB28 & $\begin{array}{c}24 \mathrm{~mm} \\
\text { IDC } \\
\text { Grade3 } \\
\text { LN involvement } \\
\text { ER- }\end{array}$ & NHPL57 & $\begin{array}{c}23 \mathrm{~mm} \\
\text { ILC } \\
\text { Grade3 } \\
\text { No LN involvement } \\
\text { ER+ }\end{array}$ \\
\hline PRFD45 & $\begin{array}{c}40 \mathrm{~mm} \\
\text { IDC } \\
\text { Grade2 } \\
\text { No LN involvement } \\
\text { ER+ }\end{array}$ & PTIG40 & $\begin{array}{c}35 \mathrm{~mm} \\
\text { IDC } \\
\text { Grade3 } \\
\text { LN involvement } \\
\text { ER+ }\end{array}$ \\
\hline SKOB39 & $\begin{array}{c}30 \mathrm{~mm} \\
\text { IDC } \\
\text { Grade } 2 \\
\text { No LN involvement } \\
\text { ER+ }\end{array}$ & GRYD52 & $\begin{array}{c}35 \mathrm{~mm} \\
\text { IDC } \\
\text { Grade3 } \\
\text { LN involvement } \\
\text { ER+ }\end{array}$ \\
\hline
\end{tabular}

IDC - invasive ductal carcinoma, ILC - invasive lobular carcinoma, LN - lymph nodes, Grade 2 - cancer localised and $<5 \mathrm{~cm}$, Grade 3 - cancer in breast and LN.

\section{Breast Cancer Cell Line MCF7}

$\mathrm{MCF} 7$, an oestrogen receptor (ER) positive breast cancer cell line was used for preliminary experiments. Cells were seeded at $3 \times 10^{6}$ cells in Complete Medium ((CM) Roswell Park Memorial Institute (RPMI) 1640 without L-Glutamine (GIBCO Life Technologies) + GPS solution (GIBCO Life Technologies) and $10 \%$ heat inactivated foetal calf serum (FCS) (JRH Industries). Cells were placed in a $\mathrm{CO}_{2}$ incubator (Quantum Scientific) at $37^{\circ} \mathrm{C}$. When the adherent MCF7 cells reach confluence, they were detached using one of two solutions. After removal of the $\mathrm{CM}$ and rinsing the flask with PBS, Versene (0.53mM EDTA (Sigma) in PBS) or a Trypsin solution $(0.1 \%$ Trypsin (Sigma) with $0.5 \mathrm{mM}$ EDTA in PBS) was added, depending on the subsequent use of the cells, and the flask placed back in the $37^{\circ} \mathrm{C}$ incubator for 5 mins. After detachment, the same quantity of CM was added to halt the detachment reaction.

\section{Basement Membrane}

Matrigel (BD Biosciences Pharmingen) is a commercial basement membrane extracted from a mouse sarcoma. Matrigel will solidify at $10^{\circ} \mathrm{C}$, therefore all implements and solutions used with this material must be cold. Matrigel solidifies on injection into the mouse to form a plug.

\section{Tumour Inoculation}

A dose finding experiment was conducted with the MCF7 cells to determine if a correlation existed between the number of cells inoculated and tumour size. Primary tumour cells were enumerated and all cells were used to inoculate the mice. Tumour cells in PBS were drawn up into an insulin syringe with a 27 gauge needle and then ejected into an ampoule containing $50 \mu \mathrm{L}$ of Matrigel for MCF7 cells and $100 \mu \mathrm{L}$ of Matrigel for primary tumour cells. The mouse was then restrained and using forceps the abdominal skin is 
raised (tenting method) and the injection given SC into the inguinal mammary fat pad area (MFP) (Fig. 1A and B).

\section{Animal Monitoring and Lump Volume}

Mice were monitored daily for well being and tumour development. Tumour size, weight of mouse, fur ruffling and hunched posture were allocated a score of 0 for no manifestation of the relevant characteristic through a subjective gradient to 1 for a severe manifestation of the characteristic. The scores were allocated and added for each characteristic each time the tumour volume was measured. A combined score of 4 required the animal be euthanased. Mice were culled using $\mathrm{CO}_{2}$ asphyxiation and cervical dislocation when their tumour size exceeded $1 \mathrm{~cm}$, overall score reached 4 , or 3 months post inoculation, whichever came first.

\section{Organ and Tumour Harvest}

After sacrifice, the tumour was excised for immunohistochemistry to reveal ER status and presence of mitotic cells. Mouse liver, lungs and bones were harvested, their gross morphology examined for tumours and then placed in formalin for identical immunohistochemical analyses as those performed on the primary breast tumour.

\section{Cytospin}

Cytospins of MCF7 cells and primary tumour cells were immersed immediately in 96\% ethanol (Banksia Scientific)
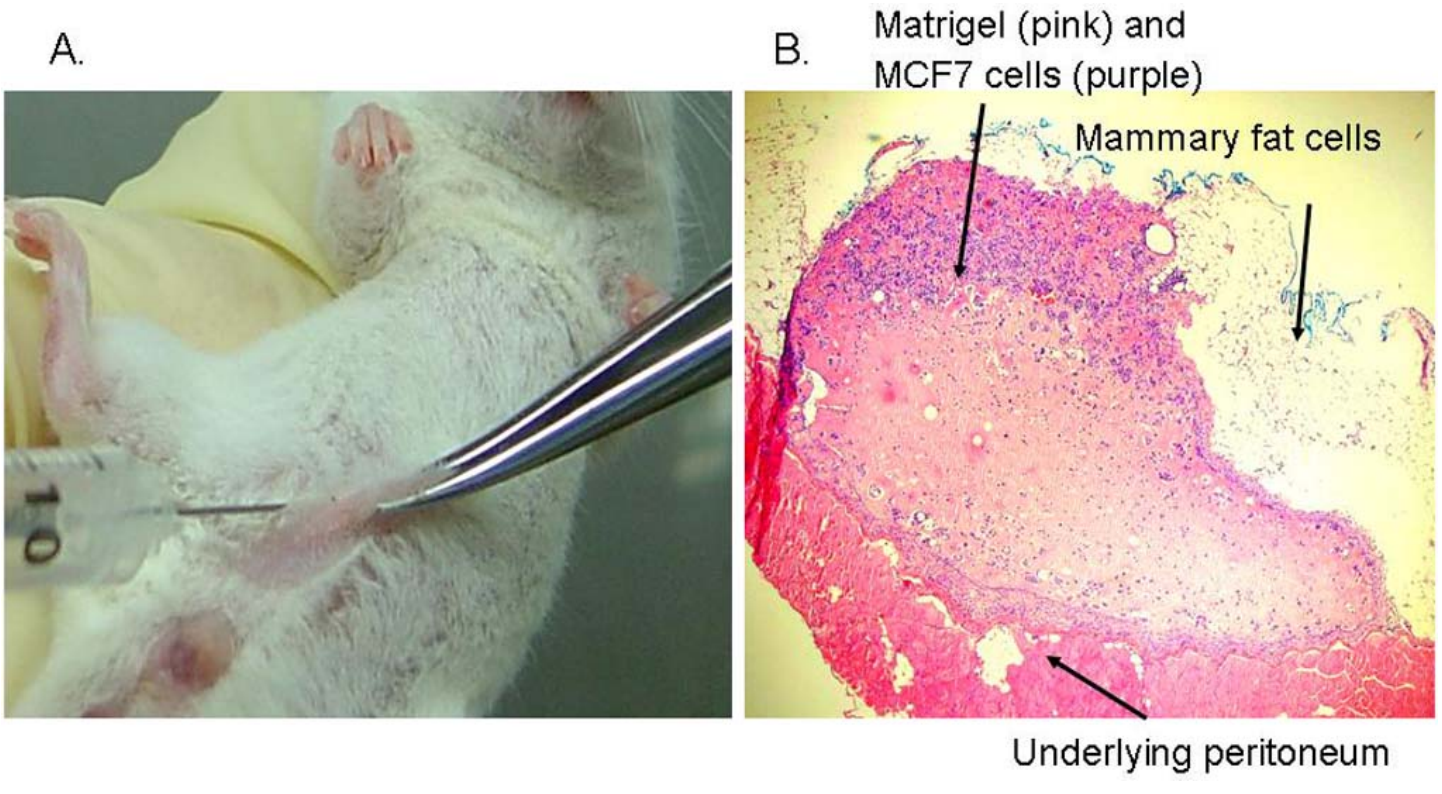

Underlying peritoneum

Fig. (1) A. SC inoculation of tumour cells in murine MFP using the tenting method. B. SC inoculation of MCF7 cells in murine MFP in situ. MCF7 cells coinoculated with 50 $\mu \mathrm{L}$ Matrigel, H\&E stain, magnification 10x4x, 9 days post inoculation.

Table 2. Flow Cytometry Antibodies Used

\begin{tabular}{|c|c|c|c|c|}
\hline Name & Fluorchrome & Specificity & Isotype & Supplier \\
\hline \hline CD24 & PE & Anti human glycoprotein & Mouse IgG2 & BD Biosciences Pharmingen \\
\hline CD44 & APC & Anti human Pgp-1 & Mouse IgG2 ${ }_{\mathrm{b}}$ & BD Biosciences Pharmingen \\
\hline BC2 & FITC & Anti human MUC1 & Mouse IgG1 & Associate Professor Mike McGuckin, MMRI \\
\hline
\end{tabular}

to fix for ER (Novacastra) staining. Cytospins were made before and after passage in the NOD/SCID mouse.

\section{Histochemistry}

Tumour, organs and bones were harvested from mice and fixed immediately in formalin. These were then embedded in paraffin blocks (bones required prior decalcification) and processed using standard protocols for anti-human ER or haematoxilin and eosin (H\&E) stain (Gurr and Amber Scientific respectively). Microscopic examination (Olympus BX60) and photography (Olympus DP12) were then used to ascertain presence of tumour cells. Cells sizes were determined using a graduated eyepiece and calibrated slide. Photographs were not manipulated with exception for adjusting for brightness and contrast.

\section{Flow Cytometry}

MCF7 cells clump in solution, so they were passed through a 23 gauge needle to ensure a single cell suspension for staining with the antibodies listed in Table 2. 10000 events were collected using FACSCalibur (Becton Dickinson). Subsequent analysis utilised FCS Express 1 and 2 software (De Novo).

\section{Statistics}

In situ tumour size was measured with digital calipers (Kinchrome). We found that the tumours resembled only 
half an ellipsoid, as they did not penetrate below the peritoneum, therefore the formula used to measure lump volume was that of half an ellipsoid, $l \times w^{2} \times \Pi / 12$. Table and graphs shown relate to lump volumes at day 64 post inoculation for consistency between animals. Statistical analysis was done on lump volumes calculated over the entire life span of each individual mouse. ANOVA, student's t test and correlations were used to analyse the data. $\mathrm{p}<0.05$ was considered to be statistically significant.

\section{RESULTS}

\section{The Importance of Matrigel to Tumour Engraftment and Growth of Primary Tumour Cells and MCF7 Cells}

Preliminary experiments using MCF7 cells without Matrigel showed no tumour engraftment at sacrifice 6 weeks post inoculation (data not shown). Beckhove and colleagues had used $200 \mu \mathrm{L}$ of Matrigel with their MCF7 cells [11]. In this project, $200 \mu \mathrm{L}$ of Matrigel produced a lump upon SC injection into the mouse that contravened our ethics approval. $100 \mu \mathrm{L}$ of Matrigel was then arbitrarily chosen to use with the reduced number of primary tumour cells available. The large lump volume measured after the inoculation of $10^{6}$ primary tumour cells in $100 \mu \mathrm{L}$ Matrigel $\left(\sim 195 \mathrm{~mm}^{3}\right)$ raised concern as to the lump volume potentially produced by the inoculation of $5 \times 10^{6}$ MCF7 cells in $100 \mu \mathrm{L}$ of Matrigel. Subsequent use of $50 \mu \mathrm{L}$ Matrigel was found sufficient for MCF7 tumour cell engraftment and growth.

\section{Defining Lump Volume Change due to Matrigel Absorp- tion Only}

In a model that is being developed to test for tumour cell cytolysis, it was important to ascertain how much of any lump volume decrease was caused by Matrigel absorption only. Matrigel forms a plug upon SC injection into the mouse. As a preliminary experiment, lump measurements were taken at 45 minutes and 9 days post injection with $50 \mu \mathrm{L}$ of Matrigel. After 45 minutes, the plug was approximately $70 \mathrm{~mm}^{3}$. After 9 days, the lump was $30 \mathrm{~mm}^{3}$. This is evidenced by the general lump volume reduction for the first 14 days post inoculation, as shown in Fig. ( $2 \mathbf{A}$ and $\mathbf{B})$. Tumour growth was therefore calculated using lump volume at 14 days post inoculation as the starting value.

\section{Influence of Tumour Cell Dosage and TBI on MCF7 Tumour Growth}

Given that Matrigel is essential for $100 \%$ tumour cell engraftment and growth of MCF7 cells, we next evaluated the role of tumour cell number and prior TBI in promoting MCF7 tumour growth. Each of the following MCF7 cell dosages, $10^{4}, 10^{5}, 10^{6}$ and $5 \times 10^{6}$, was inoculated into replicate NOD/SCID mice, one of which had received 250cGy radiation 24 hours prior to tumour cell inoculation. Tumour cell engraftment occurred in all cases, however the radiation appeared detrimental to tumour growth (Fig. 2A), compared to tumour growth in the non-irradiated mice (Fig. 2B). Starting lump volume is different in each case, depending on spread of the MCF7 tumour cell/Matrigel inoculum over the peritoneum post injection. However, rates of growth after that initial 14 days in which Matrigel absorption occurs most markedly, suggest that smaller tumours were obtained in the irradiated mice as compared with the non-irradiated mice at the final time point (Table 3 ). In the non-irradiated mice, the larger the MCF7 inoculum the larger the final tumour size $(\mathrm{p}=0.006)$. The Matrigel only control in the non-irradiated mice showed an unexpectedly large drop in volume, -22 $\mathrm{mm}^{3}$, from week 2 to week 9 post inoculation. A control mouse, which had been inoculated with killed MCF7 cells
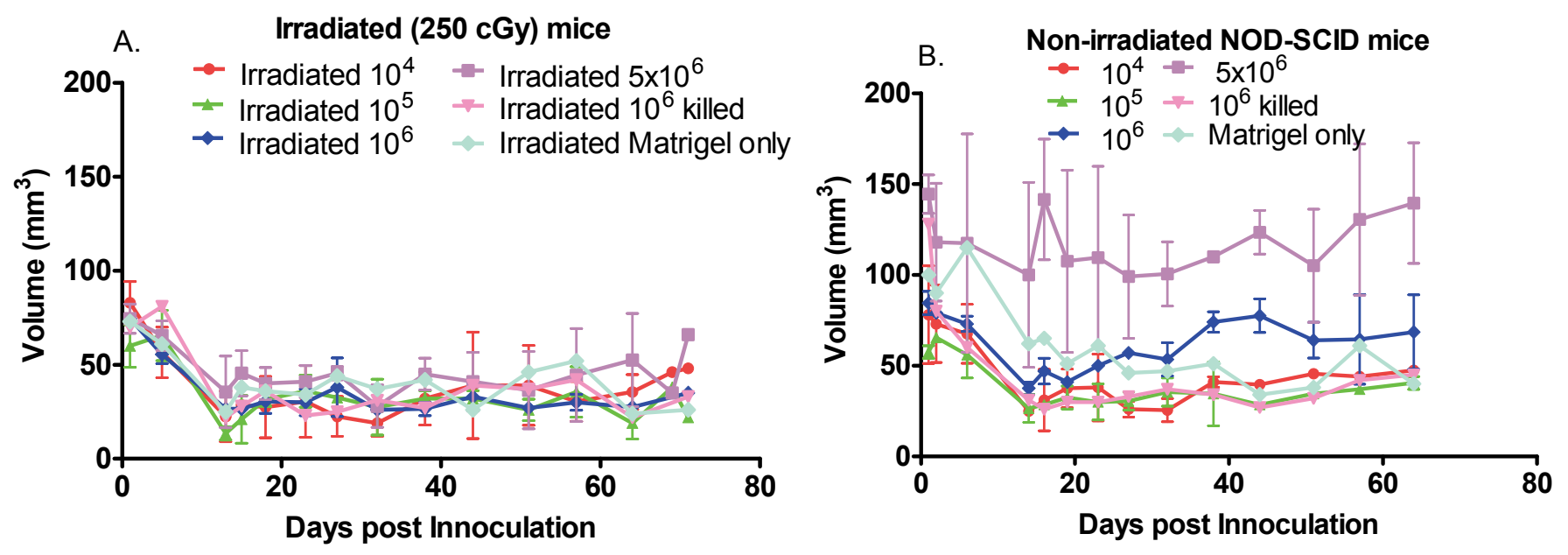

Fig. (2) A. Lump volume after MCF7 inoculation and TBI. Lump volume of $10^{4}, 10^{5}, 10^{6}$ and $5 \times 10^{6}$ MCF7 cells coinoculated with $50 \mu \mathrm{L}$ of Matrigel into mice that have received TBI of $250 \mathrm{cGy} 24 \mathrm{hrs}$ prior to inoculation. Lump measurements taken on average once per week. B. Lump volume after MCF7 inoculation without TBI. Lump volume of $10^{4}, 10^{5}, 10^{6}$ and $5 \times 10^{6}$ MCF7 cells coinoculated with 50 $\mu \mathrm{L}$ into mice that have not received TBI. Lump measurements taken on average once per week. 
Table 3. MCF7 Cell Dosage Experiment

\begin{tabular}{|c|c|c|c|c|c|c|c|c|c|c|}
\hline \multicolumn{11}{|c|}{ Irradiated Mice } \\
\hline $\begin{array}{l}\text { Days Post } \\
\text { Inoculation }\end{array}$ & $\begin{array}{c}\text { C12M0 } \\
10 \mathrm{e} 4\end{array}$ & $\begin{array}{c}\text { C12M1 } \\
10 \mathrm{e} 4\end{array}$ & $\begin{array}{c}\text { C12M2 } \\
10 \mathrm{e} 5\end{array}$ & $\begin{array}{c}\text { C12M3 } \\
10 \mathrm{e} 5\end{array}$ & $\begin{array}{c}\text { C12M4 } \\
10 \mathrm{e} 6\end{array}$ & $\begin{array}{c}\text { C12M5 } \\
10 \mathrm{e} 6\end{array}$ & $\begin{array}{l}\text { C13M2 } \\
5 \times 10 e 6\end{array}$ & $\begin{array}{l}\text { C13M3 } \\
5 \times 10 e 6\end{array}$ & $\begin{array}{c}\text { C13M4 } \\
10 \mathrm{e} 6 \\
\text { killed }\end{array}$ & $\begin{array}{c}\text { C13M5 } \\
\text { 10e4 } \\
\text { Matrigel } \\
\text { only }\end{array}$ \\
\hline 14 & 13 & 32 & 16 & 11 & 27 & 26 & 49 & 22 & 22 & 25 \\
\hline Increase $\left(\mathrm{mm}^{3}\right)$ & 16 & 10 & 9 & 2 & 1 & 1 & 21 & 13 & 0 & -1 \\
\hline Cells $/ \mu$ L Matrigel & 200 & 200 & 2000 & 2000 & 20000 & 20000 & 100000 & 100000 & & \\
\hline \multicolumn{11}{|c|}{ Non-Irradiated Mice } \\
\hline 14 & 26 & 24 & 32 & 21 & 40 & 35 & 136 & 64 & 31 & 62 \\
\hline 64 & 47 & 48 & 43 & 38 & 54 & 83 & 163 & 116 & 45 & 40 \\
\hline Increase $\left(\mathrm{mm}^{3}\right)$ & 21 & 24 & 15 & 17 & 14 & 48 & 27 & 52 & 14 & -22 \\
\hline Cells/ $\mu$ L Matrigel & 200 & 200 & 2000 & 2000 & 20000 & 20000 & 100000 & 100000 & & \\
\hline
\end{tabular}

C- cage number. M - mouse number. MCF7 cell dosage given to each mouse below mouse ID. Lump size in mm ${ }^{3}$ at days 14 and 64 post inoculation.

had an unexpected increase in lump volume $\left(14 \mathrm{~mm}^{3}\right)$. These MCF7 cells had received 10000 cGy radiation prior to inoculation. Subsequent H\&E staining of the excised lump on sacrifice revealed the MCF7 cells in this negative control had a lacy appearance, therefore could be considered to be dead MCF7 cells (data not shown).

\section{Tumour Engraftment and Growth of Primary Tumour Cells}

Six primary breast tumours were available for this study. MOPB28 and PTIG40 were inoculated into irradiated mice with no Matrigel, NHPK57 was inoculated into an irradiated mouse with $100 \mu \mathrm{L}$ Matrigel, PRFD45 and SBOK39 were inoculated into mice with no TBI and $100 \mu \mathrm{L}$ Matrigel and GRYD52 into a mouse with no TBI and no Matrigel. Only the primary tumour cells co-inoculated with $100 \mu \mathrm{L}$ Matrigel proliferated ( $p=0.003$ Fig. 3). Tumour cells injected without Matrigel failed to engraft and grow (data not shown). When Matrigel was used, there was no correlation between number of cells in the inoculum and the eventual tumour size $(\mathrm{p}=0.332)$ (Table 4).

\section{Determination and Maintenance of $\mathrm{CD}^{+}, \mathrm{CD}^{+}, \mathrm{BC2}$ (MUC1) $^{+}$and $\mathrm{ER}^{+}$Status of MCF7 Cells}

The prospective phenotype of primary breast tumour stem cells has recently been described as CD $24^{\text {low }} / \mathrm{CD} 44^{\text {high }}$ [16]. BC2 and ER are expressed on MCF7 cells [18]. It was therefore important to establish that MCF7 cells maintained their nuclear and surface marker phenotype throughout their proliferation in the mouse. There was no significant differ- ence in CD24, CD44 and BC2 expression levels on cultured MCF7 cells and those MCF7 cells that have been passaged in the mouse for 13 weeks $(\mathrm{p}=0.83$; Table 5).

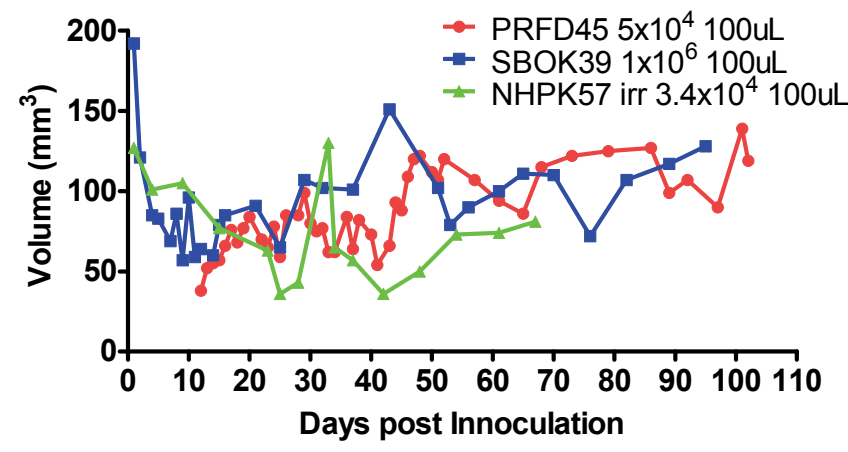

Fig. (3). Lump volume in mice inoculated with dissociated primary breast cancer cells. Dissociated primary tumour cells coinoculated with $100 \mu \mathrm{L}$ of Matrigel. $5 \times 10^{4}$ PRFD45 cells and $10^{6}$ SBOK39 cells into mice with no TBI and $3.4 \times 10^{4}$ NHPK57 into a mouse having undergone prior TBI.

\section{Histology}

Each lump was excised after sacrifice to ensure that tumour cells were proliferating, as evidenced by the presence of mitotic cells. These proliferating cells were found in both 
Table 4. Primary Tumours

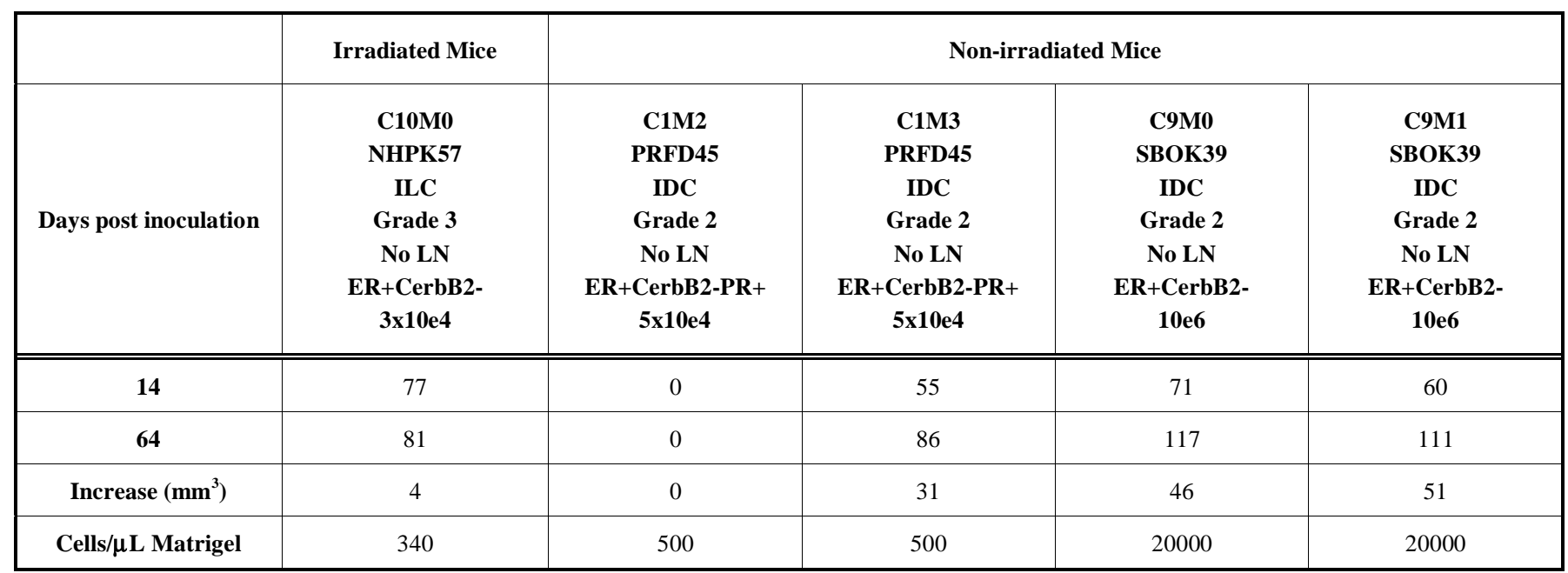

C- cage number, M - mouse ID, LN - lymph node, ILC - invasive lobular carcinoma, IDC - invasive ductal carcinoma. Primary tumour source, type and cell dosage given to each mouse below mouse ID. Lump size in $\mathrm{mm}^{3}$ at days 14 and 64 post inoculation.

Table 5. Surface Markers on MCF7 Cells befor and after In Vivo Growth

\begin{tabular}{|c|c|c|c|}
\hline & CD24+ Cells (\%) & CD44+ Cells (\%) & BC2+ Cells (\%) \\
\hline \hline Cultured MCF7 cells & 84 & 40 & 63 \\
\hline Ex vivo C3M4 & 97 & 43 & 61 \\
MCF7 cells 13 weeks post inoculation & & & \\
\hline
\end{tabular}

MCF7-derived tumours (Fig. 4) and primary tumours. Cross sectional analysis of the excised tumours showed living cells towards the outside margins of the tumour $\left(\mathrm{ER}^{+}\right.$staining) and necrotic cells in the centre (lacy appearance of cells) as shown in Fig. (5). The clear area in the middle is the Matrigel.

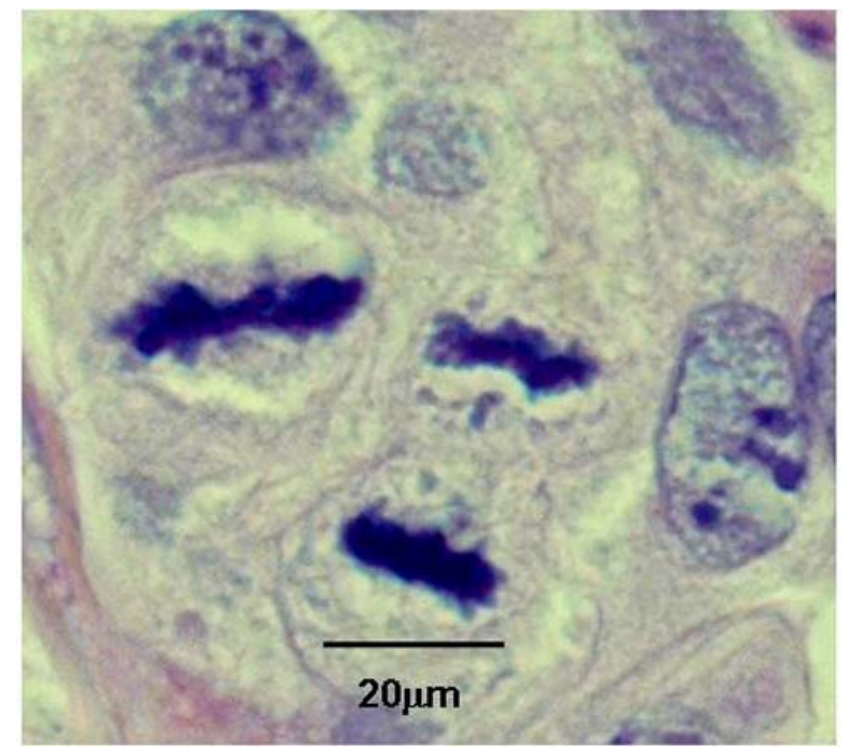

Fig. (4). MCF7 cells undergoing mitosis in excised tumour 9 weeks post inoculation. No TBI, $5 \times 106$ MCF7 cells co-inoculated with $50 \mu \mathrm{L}$ Matrigel, H\&E stain, magnification 10x100x oil.

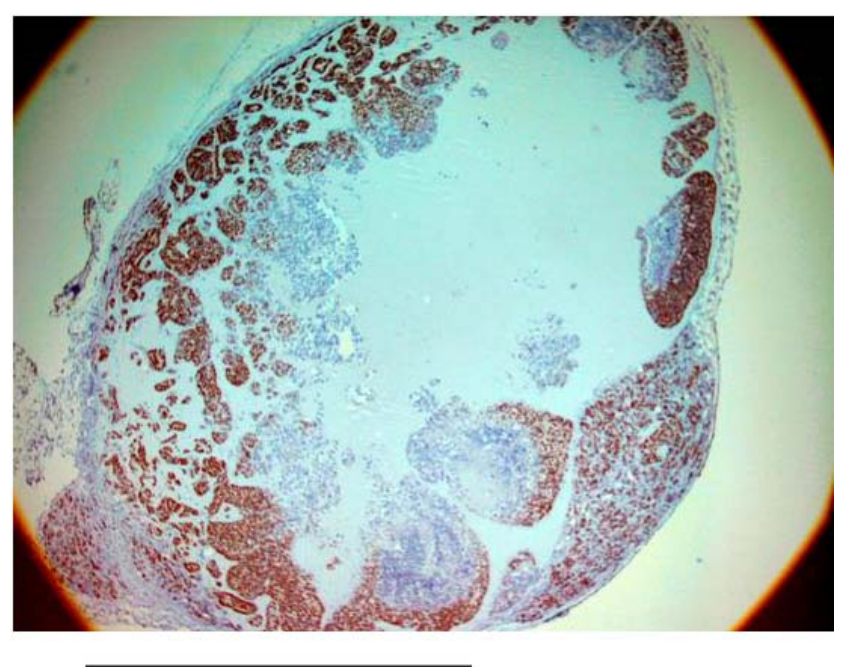

$2 \mathrm{~mm}$

Fig. (5). Retention of nuclear markers on MCF7 cells after passage in the NOD-SCID mouse. Brown stained, ER+ MCF7 cells on the periphery of this excised tumour 9 weeks post inoculation. Unstained cells in the interior have the lacy appearance of necrotic cells. No TBI, $10^{4}$ MCF7 cells coinoculated with $50 \mu \mathrm{L}$ Matrigel, ER stain, magnification $10 x 4 x$.

\section{Angiogenesis and Metastasis}

The vascularisation of breast tumours facilitates metastasis and the maintenance of the minimal residual disease. 
Both MCF7 and primary xenografts, exhibited surface (Fig. 6A) and internal vascularisation (Fig. 6B) at sacrifice that was not evident in Matrigel only controls (Fig. 6C). The tumour, murine bones, liver and lungs were harvested upon sacrifice. No metastatic breast tumour cells were identified in any organs tested with anti-human ER.

\section{DISCUSSION}

Recently, the most successful rates of engraftment and growth of xenografted human breast tumours in the nonconditioned NOD/SCID mouse were obtained by surgical implantation by the Beckhove group [11]. The appeal of the model described here is its ease of achieving human breast tumour cell growth in a mouse without the need for anaesthesia, surgery and post operative animal isolation and care. The tenting method invariably leads to the inoculum going $\mathrm{SC}$ as required. To achieve tumour growth, pre-treatment of the mouse with TBI is unnecessary. Unlike MCF7 cells, there was no correlation between numbers of primary tumour cells and tumour growth. This no doubt illustrates the diverse nature of the cells in a human breast tumour, which include stromal, normal epithelial cell and tumour cells. Whilst Matrigel provides an ideal environment for tumour cell engraftment, growth and vascularisation, its presence does impose some limitations to the model. Firstly, it is very viscous and agitation for mixing will produce bubbles. Too many bubbles will prevent efficient inoculation and a wasted sample. A delicate balance is required to mix the tumour cells with Matrigel but not introduce excessive amounts of air into the sample. Secondly, as evidenced in the negative controls, variations in size of the Matrigel plug need to be considered when calculating tumour volume. Matrigel decreases in volume over the first 2 weeks post inoculation, but as the Matrigel-only controls indicate, that may or may not be the end of its absorption. Some tumours had ill-defined edges, making precise measurements of length and width difficult. This was illustrated with the negative control inoculated with Matrigel and killed MCF7 cells, whose lump measurements increased, but histology confirmed no live cells present. $100 \%$ of tumours underwent angiogenesis (Fig. 6A and $\mathbf{B}$ ), suggesting metastasis might occur in the future. There was no evidence of metastatic $\mathrm{ER}^{+} \mathrm{MCF} 7$ cell deposits in any murine organs investigated. Thompson and colleagues found a MCF7variant tumour would metastasise in nude mice after 5 months of growth [19]. The size of murine capillaries compared to the size of human tumour cells should not pose a barrier as murine monocytes are of similar size to human tumour cells. It has been shown that metastatic lung foci from a xenografted human breast tumour could not be expected before the tumour reached $500 \mathrm{~mm}^{3}$ [20]. With average final tumour volume attained in the allotted time for this study for this project an order of magnitude lower than $500 \mathrm{~mm}^{3}$, it was perhaps optimistic to search for metastatic deposits. Flow cytometry may be used to identify circulating human tumour cells in murine blood. The $100 \%$ rate of neovascularisation of the in vivo xenografted tumours in this model might also interest those researchers interested in antiangiogenesis studies as adjuvant therapy for solid cancers.

\section{CONCLUSION}

This method facilitates $100 \%$ human breast tumour cell growth in an immunodeficient murine model, without preconditioning with TBI and in conjunction with the commercial basement membrane, Matrigel. It provides a basic model that can be used to accommodate testing of novel immunotherapies or anti-angiogenesis adjuvant therapies.

\section{ABBREVIATIONS}

NOD/SCID $=$ Non obese diabetic/severe combined immunodeficiency

SC $=$ Subcutaneous

ER $=$ Oestrogen receptor

TBI $=$ Total body irradiation

MFP $=$ Mammary fat pad

\section{A. Neovascularisation}

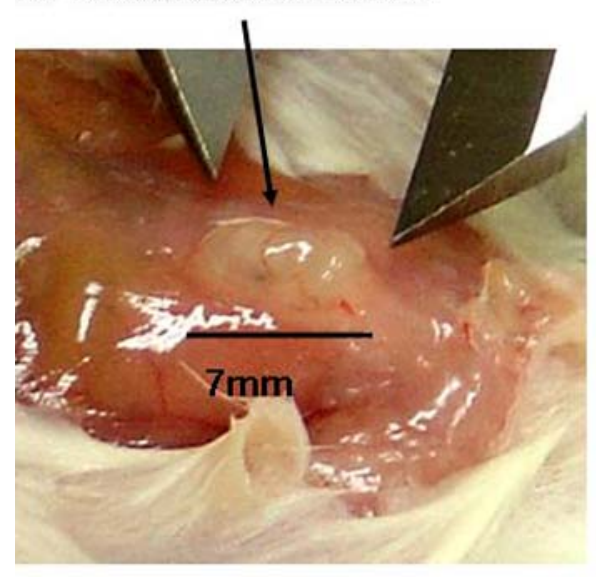

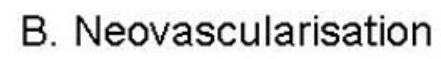

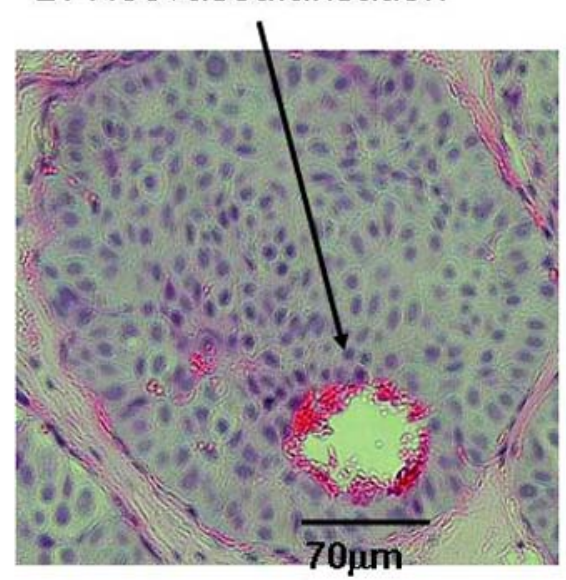

C. No neovascularisation

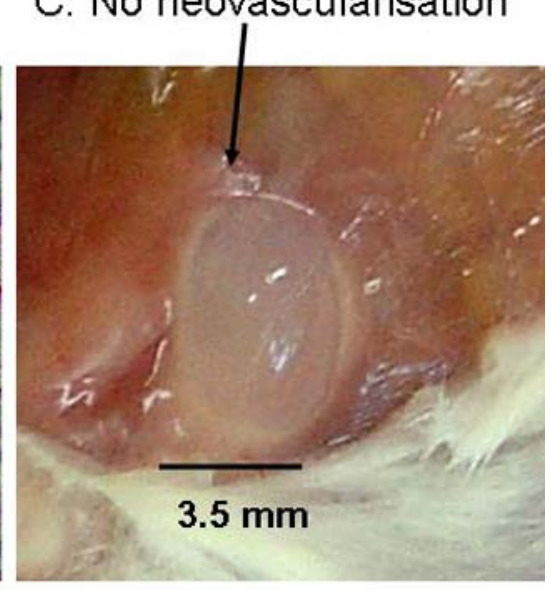

Fig. (6) A. Angiogenesis of MCF7 tumours in situ 9 weeks post inoculation. Surface vascularisation of tumour in a non-irradiated mouse, $10^{5}$ MCF7 cells coinoculated with 50 $\mu \mathrm{L}$ Matrigel. B. Angiogenesis of primary tumours in situ 9 weeks post inoculation. Surface vascularisation of tumour in a non-irradiated mouse, $10^{6}$ SBOK39 primary tumour cells coinoculated with $100 \mu \mathrm{L}$ Matrigel, H\&E stain, magnification

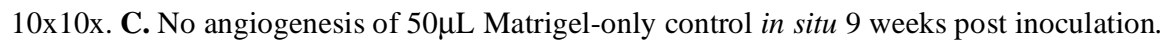




$$
\begin{array}{ll}
\mathrm{H} \& \mathrm{E} & =\text { Haematoxilin and eosin } \\
\text { IDC } & =\text { Invasive ductal carcinoma } \\
\text { ILC } & =\text { Invasive lobular carcinoma } \\
\text { LN } & =\text { Lymph nodes }
\end{array}
$$

\section{AUTHORS' CONTRIBUTIONS}

Viv Peut acquired all the data, with half analysis and interpretation of data, partial design of experiments and drafted the manuscript. Alison Rice provided funding and supervision for the project, initial concept and subsequent partial design of experiments, half analysis and interpretation of data and revised the manuscript.

\section{ACKNOWLEDGEMENTS}

We would like to thank the women that kindly donated their tumour samples. We also acknowledge Ann-Marie Burns and Georgina Crosbie (MMRI), Dr John Bell, Peter Dash and Greg Bowlay (Mater Adult Hospital (MAH) Histopathology), Drs. Pyke and Turkiewicz (MAH), Bernie Bredhauer and Michael Uren for their excellent assistance. Mater Medical Research Institute is affiliated with the University of Queensland.

\section{REFERENCES}

[1] Hanna N, Fidler IJ. Expression of metastatic potential of allogenic and xenogeneic neoplasms in young Nude mice. Can Res 1981; 41: 438-44.

[2] Levy JA, White AC, McGrath CM. Growth and histology of a human mammary carcinoma cell line at different sites in the athymic mouse. Br J Cancer 1982; 45: 375-83.

[3] Sharkey FE, Fogh J. Metastasis of human tumors in athymic Nude mice. Int J Cancer 1979; 24: 733-8.

[4] Steel GG, Courtenay VD, Rostom AY. Improved immune suppression techniques for xenografting of human tumors. Br J Cancer 1978; 37: 224-30.

[5] Zietman AL, Sugiyama E, Ramsay JR, et al. A Comparative-Study on the Xenotransplantability of Human Solid Tumors into Mice with Different Genetic Immune Deficiencies. Int J Cancer 1991; 47: 755-9.

[6] Bosma GC, Custer RP, Bosma MJ. A severe combined immunodeficiency mutation in the mouse. Nature 1983; 301: 527-30.
[7.] Kubota T, Yamaguchi H, Watanabe M, et al. Growth of Human Tumor Xenografts in Nude-Mice and Mice with Severe Combined Immunodeficiency (Scid). Surgery Today- Japanese J Surg 1993; 23(4): 375-7.

[8] Visonneau S, Cesano A, Torosian MH, Santoli D. Cell therapy of a highly invasive human breast carcinoma implanted in immunodeficient (SCID) mice. Clin Canc Res 1997; 3: 1491-1500.

[9] Visonneau S, Cesano A, Torosian MH, Miller EJ, Santoli D. Growth characteristics and metastatic properties of human breast cancer xenografts in immunodeficient mice. Am J Pathol 1998; 152: 1299-311.

[10] Shultz LD, Schweitzer PA, Christianson SW, et al. Multiple defects in innate and adaptive immunological function in Nod/LtszScid mice. J Immunol 1995; 154: 180-91.

[11] Beckhove P, Schutz F, Diel IJ, et al. Efficient engraftment of human primary breast cancer transplants in nonconditioned NOD/Scid mice. Int J Cancer 2003; 105: 444-53.

[12] Bai L, Beckhove P, Feuerer M, et al. Cognate interactions between memory $\mathrm{T}$ cells and tumor antigen-presenting dendritic cells from bone marrow of breast cancer patients: bidirectional cell stimulation, survival and antitumor activity in vivo. Int J Cancer 2003; 103: 73-83.

[13] Feuerer M, Beckhove P, Bai L, et al. Therapy of human tumors in NOD/SCID mice with patient-derived reactivated memory $T$ cells from bone marrow. Nat Med 2001; 7: 452-8.

[14] Alberts B, Johnson A, Lewis J, Raff M, Roberts K, Walter P. Molecular Biology of the Cell. New York: Garland Science; 2002.

[15] White L, Sterling-Levis K, Kees UR, Tobias V. Medulloblastoma/primitive neuroectodermal tumour studied as a Matrigel enhanced subcutaneous xenograft model. J Clin Neurosci 2001; 8: 151-6.

[16] Al-Hajj M, Wicha MS, Benito-Hernandez A, Morrison SJ, Clarke MF. Prospective identification of tumorigenic breast cancer cells. Proc Natl Acad Sci USA 2003; 100: 3983-8.

[17] Beckhove P, Feuerer M, Dolenc M, et al. Specifically activated memory $\mathrm{T}$ cell subsets from cancer patients recognize and reject xenotransplanted autologous tumors. J Clin Invest 2004; 114: 6776.

[18] Botti C, Seregni E, Lombardo C, Massaron S, Bombardieri E. Effects of steroid-free fetal serum and steroid supplementation on MUC1 gene expression in human breast cancer cell line MCF7. Anticancer Res 1997; 17: 205-8.

[19] Thompson EW, Brunner N, Torri J, et al. The invasive and metastatic properties of hormone-independent but hormone-responsive variants of MCF7 human breast cancer cells. Clin Expt Metastasis 1993; 11: 15-26.

[20] Hurst J, Maniar N, Tombarkiewicz J, et al. A novel model of a metastatic human breast tumor xenograft line. Br J Cancer 1993; 68: 274-276. 